\title{
Augmentative And Alternative Communication Systems For Post-Stroke Patients With Severe Communication And Motor Impairment
}

\author{
Talieh Zarifian $^{1 *}$, Amin Mahnam ${ }^{2}$, Atabak Vosoughi ${ }^{3}$ \\ ${ }^{1}$ Assistant Professor of Speech Therapy Department, University of Social Welfare and Rehabilitation Sciences, Tehran, \\ Iran. \\ ${ }^{2}$ Assistant Professor of Biomedical Engineering, Engineering Faculty University of Isfahan, Isfahan, Iran. \\ ${ }^{3}$ Head of Beautiful Mind Institute, M ember of Rehabilitation Advisory Committee of Health M inistry, Tehran, Iran. \\ *Corresponding Author: Email: ta.zarifian@uswr.ac.ir
}

Background and aims: Adults with acquired neurological disorders (stroke, Traumatic Brain Injury ...) develop their verbal communication and literacy capabilities as typical speakers and writers. They use these skills to participate academically, vocationally, recreationally, and socially. Depending upon their neurological condition, they gradually or suddenly lose their speech or language capabilities and are required to rely on Augmentative and Alternative Communication (AAC) systems to meet their communication needs. In addition to the loss of their spoken communication, the impact of their neurological condition on their participation patterns is potentially profound with reduced ability to care for themselves, a reduction or loss of employment, and usually a sudden or gradual restriction of their social networks. AAC is an umbrella term that encompasses the communication methods used to supplement or replace speech or writing for those with impairments in the production or comprehension of spoken or written language. During the past five decades, AAC technologies have been developed to compensate for these natural communication losses.

Stroke is one of the main causes of disability in the world. About $20 \%$ of stroke patients experience aphasia, with $20-30 \%$ of these individuals exhibiting severe communication deficits for at least a portion of their recovery period. Augmentative and Alternative Communication (AAC) encompasses the communication methods used to supplement or replace speech or writing for those with impairments in the production of spoken or written language. Specifically designed Human Computer Interfaces $(\mathrm{HCl})$, as an assistive technology, provides new channels of communication for patients with aphasia, dysarthria, and dyspraxia, when accompanied by movement impairments.

In this workshop after stating a science review of the following types of issues: AAC acceptance (individually, culturally); AAC availability; AAC use patterns; AAC limitations are main issues, an AAC technology for post-stroke patients will be presented which developed by a knowledgebase company in Iran. The system allows patients with communication and motor impairment to state their intentions and feelings by a minimum movement in their body, or just by moving their eyes. Different sensors and switches are available to adopt based on the limited ability of the patients. For detecting eye movements, a novel wearable miniaturized system has been developed that is worn as a headband and detects eye movements based on processing electro-oculogram. A high performance graphical user interface has been developed to type letters and numbers in Persian language. The system also provides words prediction, text to speech conversion with natural voice, and sending/receiving messages in the mobile networks for a convenient communication experience. The developed system has been tested successfully by more than 20 patients with different disabilities, and is now commercially available.

The proposed system can also help the severely disabled people with amyotrophic lateral sclerosis, quadriplegia, muscular dystrophy or cerebral palsy to communicate with others and mention their intentions, needs and feelings. This low-cost wearable device assures high level of comfort for the user without fatigue and do not need long time training. The system can also be adapted for the patients who can speak, but could not move their hands, to work with the computer and enjoy using the internet.

Key words: acquired neurological disorder, stroke, Augmentative and Alternative Communication, Persian

DOI: 10.7575/aiac.abcmed.ca1.66

Published Date: February 2017

Peer-review is under responsibility of the 9th Iranian Stroke Congress.

Published by Australian International Academic Centre, Australia

This published work is open access under the CC BY license.

Available online at www.abcmed.aiac.org.au 